IT would appear that before it was isolated, the plateau was a favourable hunting ground for early man. A number of stone arrow-heads and knives have been found. Unless these are the relics of an early party of adventurous climbers, which seems unlikely, they should help in assigning a date to the period of isolation, more especially if the arrow points should conform to the highly specialized type of stone implement known as the Folsom point, which is widely distributed over the High Lands of the south-western United States from Wyoming to New Mexico, though not yet found in characteristic form in Arizona. As mentioned below, stone implements have been found recently in South America in association with the extinct horse and giant ground sloth, while Folsom points have been found embedded in the bones of an extinct bison, as well as in association with that form and with the mammoth, at Folsom and Clovis in New Mexico and elsewhere. It is now beyond question that in certain parts of North America early man was contemporary with an extinct fauna which in Europe would justify a Pleistocene dating in the later part of the Ice Age. In America, however, it is generally conceded, the characteristic Pleistocene fauna, or at least certain members of it, may have survived to a much later date than in the Old World, while conditions militated against a very early appearance of man in the New. If the implements of Shiva's Temple are of the earliest type, and belong, as appears probable, to the pre-isolation period, they indicate on a conservative estimate an upward limit for the period of isolation of approximately ten thousand years, or possibly a little but not much more.

\section{Ancient Man in Chile}

AN expedition to Chile of the American Museum of Natural History, New York, extending over a period of two and a half years, is reported to have discovered a succession of stone age industries claimed to be of greater antiquity than any previously known in South America. More than four thousand stone implements, it is stated by Science Service, Washington, D.C., have been collected by Mr. and Mrs. Junius Bird, on behalf of the Museum, from two cave sites, Fell's Cave and Palli Aike Cave on the banks of the Rio Chico in southern Chile, near the Straits of Magellan. In the former of the two caves was a stratified succession of five cultures, of which the earliest included tanged spearpoints, unique in South America, associated with the bones of the extinct horse and giant ground sloth. This culture was covered by a rockfall, while at Palli Aike, twenty miles away, the oldest culture period closes with a deposit of volcanic ash. Some considerable time after the fall of rock, Fell's Cave was again occupied by man. With the artefacts of this period are associated at first bones of the horse and ground sloth, and later of foxes, of which one form is extinct, and birds. The implements are cruder than those of the early stage. In this and the preceding period the animal bones have been split for the extraction of marrow and show the effects of fire.
The succeeding culture introduces the bola, of which the carefully grooved weights have been found with the stone gravers used to make the grooves. Arrow points and knives appear with the bola in the fourth culture, which is dated tentatively at 2000 B.c. on comparative evidence. The last occupants of the cave, who show no affinity with their predecessors, were the possessors of a culture in many ways com. parable with that of the Ona of Tierra del Fuego, who, up to a few years ago, used stone arrow-points similar to those found in the cave. The cave seems to have been abandoned before the Spanish conquest, as no bones of the horse then introduced into America have been found in it.

\section{University Development at Birmingham}

IT is reported that the University of Birmingham is selling the Mason College site, and the price is said to be $£ 400,000$. If the negotiations are satisfactorily completed, the long-desired transfer of the whole of the University to the Edgbaston site will soon be an accomplished fact, and the uneconomical and very inconvenient separation of the faculties will be a thing of the past. Already the building of the new medical school (between the great new hospital and the University at Edgbaston) is nearing completion, and it is hoped that the school will be ready for opening next year. Such an event would be a fitting crown to the work of the Vice-Chancellor (Sir Charles Grant Robertson) who has expressed his intention of retiring at the end of the coming session and who has taken a leading part in the establish. ment of both hospital and medical school. The money resulting from the sale of the Mason College site will also make possible the expansion, and improvement of the equipment, of some of the departments already at Edgbaston, the Physics Department in particular, which is at present partly housed in old Army huts, inconvenient and unsightly.

\section{Health and the Community}

Is the account of the discussion in Section I (Physiology) of the British Association on "Health and the Community", which appeared in NATuRE of September 18, p. 493 , it is stated on p. 494 that the safest rate of reproduction for both mother and offspring is the modal rate. The author of the article has asked us to point out that this statement holds for any size of family, but the example of modal rate actually given was for a family of seven. This does not bear the implication that seven is the ideal number per family. Actually the lowest mortality was found in families of three, produced at the modal rate. The author has also sent the following supplementary note. "One point in the discussion of immense importance for the future not only of the race but also threatening civilization itself, was not sufficiently stressed in the article, namely, the differential birth rate. It follows from the facts that the modal rate is, on the whole, observed only in the lowest paid members of the community, and that they start reproduction early (less than twenty years of age), that the number of the population 
below the poverty line, that is, those being maintained by the tax-payers, will steadily increase. In 1930 , round about 10 per cent of the families had more than 40 per cent of the pregnancies, 45 per cent of the still-births, 53 per cent of the infant plus child mortalities and 63 per cent of the miscarriages. In 1950 , the 10 per cent will have become at least 30 per cent. Nothing short of massacre can alter that now. Births cannot be retrospective. If nothing is done and the process goes on, in 1970, the submerged tenth will be multiplied by seven. This means that, apart altogether from the increasing load of old people, some 30 per cent of the population will have to face the problem of supporting the rest of the community."

\section{The Short-Mayo Composite Aircraft}

Expermental flights of the two units of this combination are proceeding successfully at Rochester. Mercury, a four-engined monoplane seaplane, which is to be attached to the top of, and launched from, Maia, a four-engined monoplane flying boat of a modified Empire type, have both flown separately, and have now to carry out trials, taking off, flying and landing as a combined unit. These will be followed by tests involving releasing in the air and landing as separate units, their normal functions. This experiment is one of fundamental importance in the problem of high-speed long-range flight, as it represents one of several possible methods of getting an aircraft into the air with a load which would make taking-off unsafe or even impossible for a machine under its own power. Heavy loads are not only economical from the transport point of view, but also high wing loading is essential for economical power consumption in high-speed flight. Reduction in engine power used not only reduces costs, but also increases the machine's range on a given fuel tank capacity. When this problem is successfully overcome, it will also help in the case of land aircraft, allowing the use of smaller aerodromes for large heavily loaded commercial machines.

ANother point of the composite type of aircraft is that it will allow the engines of the launched machine to be of the supercharged type necessary for high altitude flying, without their having to carry the complications necessary to allow them to function efficiently at ground level, for the purpose of taking off, as well. Other methods of attaining the same object at present being developed are (1) the use of various wing attachments such as slots or flaps, wing surface and contour changing devices, variable pitch propellers, to increase the speed range of the aircraft, and (2) catapulting the machine into the air, giving it the speed necessary for flight with its high loading, from a momentum applied to it from an external source of power, usually either explosive or hydraulic.

\section{Progress of Marine Engineering}

ON September 14, Mr. S. J. Pigott, director-incharge of the Clydebank Works of John Brown and
Co., Ltd., where the Queen Mary was built, delivered the presidential address to the Institute of Marine Engineers. In the main it was a review of the development in marine engineering during the last sixty years. The era 1877-87, he said, might be designated "The Advent of Steel in Engineering". In that decade it was possible to raise the pressure in cylindrical boilers to $160 \mathrm{lb}$. per sq. in., and at the same time forced draught was introduced. The next decade, 1887-97, saw the development of the quadruple-expansion engine, which in the period 1897-1907 attained its maximum size. The year 1897 was also marked by the use by Sir Charles Parsons of the marine steam turbine, and in 1904 the Cunard Steamship Company equipped the Carmania with a high-pressure turbine driving a centre-line shaft and exhausting to a low-pressure turbine on each wing-shaft. The Diesel engine first made its appearance on shipboard in 1903 in the small Russian tanker Vandal. Another landmark was the fitting of geared turbines in the Vespasian in 1909. In 1910 impulse turbines as opposed to the earlier reaction turbines were fitted in H.M.S. Bristol, and to-day, the most highly powered British naval vessel, H.M.S. Hood, is propelled by impulse turbines with gearing. If the era 1927-37 has seen no epochmaking development, it has produced progressive designs as is seen in the cross-channel motor-ship Prince Baudouin, the turbo-electric P. and O. liner Viceroy of India, and last but not least the Queen Mary and Normandie.

\section{Miniature Ball Bearings}

As invention which, apart from its intrinsic merits as a mechanical development, promises to be of especial interest in a scientific sense, is the introduction by a Swiss manufacturer of a range of miniature ball bearings. Ordinary bearings of this class have been made in sizes varying from half an inch to five feet in diameter overall; but nothing small enough has been available to satisfy the requirements of small and sensitive instruments. The bearings now obtainable as a result of this invention are of several different types and vary in size from 1 to 22 millimetres in diameter overall. They are thus of suitable size for use in such devices as small motors, recorders, meters, clockwork, tachometers and scientific instruments of many kinds in which measured movements are produced by infinitesimal forces, and friction must be eliminated as far as possible. Comparative tests on these bearings and the jewelled bearings they are intended to replace show advantages under three different modes of operation. The time to damp down a rotary motion was in some cases so high as eight times that when plain pivots were used and twenty times that when tapered pivots were used, though there is a good deal of variation in the results. In an oscillatory test the corresponding figures were about 4 and 15 , while in the deviation test the results claimed are also favourable. As these new bearings are obtainable at moderate prices, it is probable that, after adequate trials, they will play an important part in the 